\title{
Exacerbated grassland degradation and desertification in Central Asia during 2000-2014
}

\author{
Geli Zhang, ${ }^{1}$ Chandrashekhar M. Biradar, ${ }^{2}$ Xiangming Xiao, ${ }^{1,3,8} \mathrm{~J}_{\text {Inwei Dong, }}{ }^{4}$ Yuting Zhou, ${ }^{5}$ Yuanwei Qin, ${ }^{1}$ \\ Yao Zhang, ${ }^{1}$ Fang Liu, ${ }^{4}$ Minguun Ding, ${ }^{6}$ and Richard J. Thomas ${ }^{7}$ \\ ${ }^{1}$ Department of Microbiology and Plant Biology, and Center for Spatial Analysis, University of Oklahoma, \\ Norman, Oklahoma 73019 USA \\ ${ }^{2}$ International Center for Agricultural Research in Dry Areas (ICARDA), Amman 11195 Jordan \\ ${ }^{3}$ Ministry of Education Key Laboratory of Biodiversity Science and Ecological Engineering, Institute of Biodiversity Science, Fudan \\ University, Shanghai 200433 China \\ ${ }^{4}$ Key Laboratory of Land Surface Pattern and Simulation, Institute of Geographic Sciences and Natural Resources Research, Chinese \\ Academy of Sciences, Beijing 100101 China \\ ${ }^{5}$ Department of Plant and Soil Sciences, Oklahoma State University, Stillwater, Oklahoma 74078 USA \\ ${ }^{6}$ Key Lab of Poyang Lake Wetland and Watershed Research of Ministry of Education and School of Geography and Environment, \\ Jiangxi Normal University, Nanchang 330022 China \\ ${ }^{7}$ CGIAR Research Program on Dryland Systems, clo ICARDA, Amman 11195 Jordan
}

\begin{abstract}
Grassland degradation and desertification is a complex process, including both state conversion (e.g., grasslands to deserts) and gradual within-state change (e.g., greenness dynamics). Existing studies hardly separated the two components and analyzed it as a whole based on time series vegetation index data, which cannot provide a clear and comprehensive picture for grassland degradation and desertification. Here we propose an integrated assessment strategy, by considering both state conversion and within-state change of grasslands, to investigate grassland degradation and desertification process in Central Asia. First, annual maps of grasslands and sparsely vegetated land were generated to track the state conversions between them. The results showed increasing grasslands were converted to sparsely vegetated lands from 2000 to 2014, with the desertification region concentrating in the latitude range of $43-48^{\circ} \mathrm{N}$. A frequency analysis of grassland vs. sparsely vegetated land classification in the last $15 \mathrm{yr}$ allowed a recognition of persistent desert zone (PDZ), persistent grassland zone (PGZ), and transitional zone (TZ). The TZ was identified in southern Kazakhstan as one hotspot that was unstable and vulnerable to desertification. Furthermore, the trend analysis of Enhanced Vegetation Index during thermal growing season $\left(\mathrm{EVI}_{\mathrm{TGS}}\right)$ was investigated in individual zones using linear regression and Mann-Kendall approaches. An overall degradation across the area was found; moreover, the second desertification hotspot was identified in northern Kazakhstan with significant decreasing in $\mathrm{EVI}_{\mathrm{TGS}}$, which was located in PGZ. Finally, attribution analyses of grassland degradation and desertification were conducted by considering precipitation, temperature, and three different drought indices. We found persistent droughts were the main factor for grassland degradation and desertification in Central Asia. Considering both state conversion and gradual within-state change processes, this study provided reference information for identification of desertification hotspots to support further grassland degradation and desertification treatment, and the method could be useful to be extended to other regions.
\end{abstract}

Key words: Central Asia; drought; Enhanced Vegetation Index; gradual change; grassland degradation and desertification; MODIS; remote sensing; state conversion.

\section{INTRODUCTION}

In the context of global climate change, dryland areas are projected to increase dramatically to cover one-half of the global land surface by the end of this century, resulting in increased land degradation and desertification (Huang et al. 2015, Sternberg et al. 2015). Central Asia is a dryland hotspot dominated by moisture-limited grassland, semi-desert, and desert ecosystems (Loboda

Manuscript received 6 February 2017; revised 11 September 2017; accepted 4 October 2017. Corresponding Editor: Prasad Thenkabail.

${ }^{8}$ Corresponding author; e-mail: xiangming.xiao@ou.edu et al. 2012). Due to the relatively infertile soil and sparse vegetation cover, the grassland in Central Asia is sensitive to climate variability and human activities (Lioubimtseva and Henebry 2009, Huang et al. 2015, Seddon et al. 2016). Land reclamation during the Soviet era and cropland abandonment after the collapse of the Soviet Union have greatly affected grassland conditions in Central Asia (Wright et al. 2012). The grazing activities and livestock numbers have also greatly impacted grasslands since 1990 (Karnieli et al. 2008). Given the predicted population growth, the grassland degradation and desertification issue has been an important concern for human wellbeing in this region. It has attracted 
increasing attention on grassland degradation and desertification in Central Asia along with the enhanced warming and land cover and land use change due to human activities in the past several decades ( $\mathrm{Li}$ et al. 2013, 2015, Klein et al. 2014, de Beurs et al. 2015, Xi and Sokolik 2015, Zhou et al. 2015).

A comprehensive picture of grassland degradation and desertification in Central Asia needs a clear definition. Generally, grassland desertification is considered as the loss of the ability of a landscape to provide ecosystem services due to a change in soil properties, vegetation, or climate (D'Odorico et al. 2013). The process of grassland degradation and desertification is complex in view of the diversity of factors influencing grassland degradation and desertification, including natural factors (e.g., climate, fire, and species invasion) and anthropogenic factors (e.g., overgrazing and reclamation; Gong et al. 2015, Lin et al. 2015, Hu et al. 2016, Pereira et al. 2016). It could involve a decrease of greenness and productivity, along with biodiversity loss; but it also could relate to an increase of greenness due to shrub encroachment. In this specific study, we defined the grassland degradation and desertification as the process of loss in productivity and greenness. Grassland degradation and desertification is linked with a transition between two stable states in bi-stable ecosystem dynamics corresponding to a vegetated state and an un-vegetated state according to desertification theories (Appendix S1: Fig. S1) (D’Odorico et al. 2007, 2013). The resilience of a bi-stable system is extremely limited when compared with systems having only one stable state (Holling 1973). Thus, if an external disturbance (e.g., drought) induces a transition to an unvegetated or desertified state, the removal of this perturbation would not necessarily allow the system to spontaneously return back to its initial status.

If the disturbance is beyond a critical threshold (e.g., by reducing vegetation cover), these systems move toward the alternative stable state of degraded land (D'Odorico et al. 2013). Therefore, grassland degradation and desertification is a complex process including both state conversion (e.g., conversion from grasslands to deserts) and gradual within-state change (e.g., grassland degradation characterized by greenness decrease). The observations of desertification, including both the transition from grasslands to deserts and gradual change in greenness, are critical for getting a clear picture of grassland degradation and desertification in Central Asia.

Given the harsh environment in dryland areas and their vast geographic extent, time-series data from satellite remote sensing has been widely used for detecting large scale grassland degradation and desertification from the perspective of vegetation coverage change (Wessels et al. 2012, de Beurs et al. 2015). Remotely sensed vegetation indices, as the signal of vegetation growth, such as Normalized Difference Vegetation Index (NDVI), Enhanced Vegetation Index (EVI), Soil-
Adjusted Vegetation Index (SAVI), and Tasseled Cap Greenness (TCG), have been widely used to track changes in the vegetated land surface in dryland areas (Tucker et al. 1991, Jeong et al. 2011, de Beurs et al. 2015, Eckert et al. 2015, Sternberg et al. 2015, Zhou et al. 2015). A recent study using GIMMS3g NDVI time-series data has reported that Central Asia experienced a significantly decreasing trend of seasonal NDVI for 1992-2011 due to continued warming and socio-economic conditions (Zhou et al. 2015). de Beurs et al. (2015) found different variables (e.g., EVI, NDVI, and TCG) can reveal very similar trends for land surface dynamics. These remote sensing indicators can reflect the greenness or vegetation dynamics; however, the existing studies have not paid enough attention to the identification of three states of desertification: unvegetated (deserts) state, vegetated (grassland) state, and transitional (conversion between grassland and sparsely vegetation on the time scale) state. That is, the previous studies paid more attention to the within-state shifts of vegetation coverage, instead of the land cover conversion from grasslands to deserts.

In addition, the barren or sparsely vegetated regions with significant interannual fluctuation of vegetation index were neglected based on the conventional trend analysis in previous studies (Wessels et al. 2012, de Beurs et al. 2015). One reason is that the vegetation index values in barren or sparsely vegetated regions are largely affected by the soil background. The barren or sparsely vegetated lands are the transition ecotone from grassland (vegetated) to desert (unvegetated), and also are the most sensitive, fragile, and unstable region. This transition ecotone greatly determines the direction of desertification (turning to vegetated or unvegetated state) under external perturbation. In barren or sparse vegetated lands, the soil variations would affect the fluctuation of vegetation index value, which will not well indicate the true trends of vegetation change. Some studies just excluded the areas with very low NDVI when analyzing vegetation change at the regional scale (Zhou et al. 2001, Piao et al. 2011a, Zhang et al. 2013); doing so will miss the variation and trend information of grassland desertification. It is critical to understand the grassland degradation and desertification process and establish early warning signals of conversion from grassland to desert (Alibakhshi et al. 2017). Therefore, the classification of the persistent grassland zone (PGZ), persistent desert zone (PDZ), and unstable transitional zone (TZ) could be an effective approach to retain this important information and exert a more comprehensive understanding of grassland degradation and desertification.

Based on the above concerns and limitations of previous studies, the major objective of this study is to provide more robust satellite evidence for the grassland degradation and desertification process in Central Asia by considering both state conversions and gradual within-state changes. Specifically, we would like to 

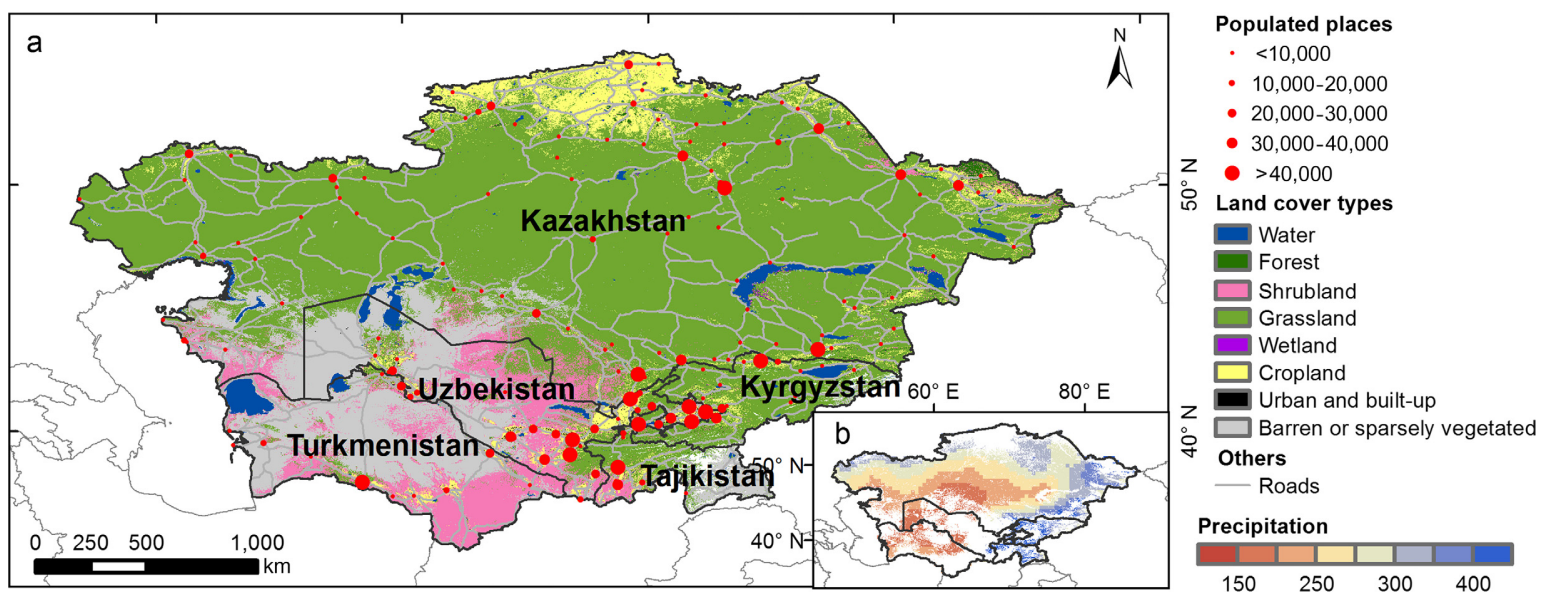

FIG. 1. Location of study area. (a) Spatial distribution of land cover types and population in Central Asia, based on the FAOSTAT data and MCD12Q1 data in 2010; (b) multi-year average precipitation during 2000-2013 in the specific targeted area of Central Asia (see Methods: Determination of targeted area by excluding croplands and forests for details).

answer three questions: (1) To what extent and where did state conversions between grassland and sparsely vegetated land take place from 2000 to 2014? (2) What was the gradual within-state trend of vegetation growth in individual zones? (3) What was the main driver for the grassland degradation and desertification process in this region? We also tried to identify the hotspots of grassland desertification in Central Asia that would be the first priority for treatment. The results are expected to serve decision makers in order to take early action to prevent further desertification in Central Asia.

\section{Materials And Methods}

\section{Study area}

Central Asia, the core region of the Asian continent, consists of Kazakhstan, Uzbekistan, Turkmenistan, Kyrgyzstan, and Tajikistan (Fig. 1a). The total area of Central Asia is about 4 million square kilometers. The total population is about 66 million in 2013-2014, the density of population is low, and the spatial distribution of population varies widely in this region. The terrain of Central Asia is high in the east but low in the west, mainly dominated by plains and hills. Central Asia includes a range of landscapes with a transition from steppes in the north to semi-deserts and deserts in the south (Gessner et al. 2013), and is dominated by grasslands. Central Asia is characterized by dry and continental climate, scarce precipitation, intensive evaporation, and large diurnal and annual fluctuation of temperatures. Temperatures and precipitation depend on the latitude and elevation in this region. Mean summer temperature is around $20^{\circ} \mathrm{C}$ in the north of Central Asia, and more than $30^{\circ} \mathrm{C}$ in the south of Central Asia. In winter, the mean temperatures are below zero all over Central Asia. Mean annual precipitation is approximately $400 \mathrm{~mm}$ in the lowlands of the north part of Central Asia (mainly north of Kazakhstan), and $<100 \mathrm{~mm}$ in parts of Central Asia (mainly Uzbekistan and Turkmenistan) (Gessner et al. 2013). Average monthly precipitation is very low in summer and early autumn from July to September, increases in October and November, and is highest in spring (March or April), followed by swift drying in May and June.

\section{Materials}

Remote sensing data.-The moderate-resolution imaging spectroradiometer (MODIS) collection products of surface reflectance (MOD09A1), land surface temperature (LST, from MOD11A2), and land cover data (MCD12Q1) were used in this study (Table 1), which were obtained from the USGS EROS Data Center, including the eight tiles (H21/22/23V03, H21/22/23V04, and H22/23V05) covering Central Asia (available online). ${ }^{9}$

Time series vegetation index data.-The vegetation indices were calculated using the 8-d composite Surface Reflectance Product (MOD09A1; Vermote and Vermeulen 1999, Zhou et al. 2015) from 2000 to 2014, including (1) EVI, which is considered to have higher robustness to atmospheric conditions and soil background relative to NDVI (Huete et al. 1997, 2002, Xiao et al. 2003), (2) land surface water index (LSWI), which is sensitive to equivalent water thickness (Xiao et al. 2002, Maki et al. 2004) because the imbedded SWIR band is sensitive to leaf water and soil moisture, and (3) normalized difference snow index (NDSI), which was used to identify snow pixels (Hall et al. 2002).

\footnotetext{
${ }^{9}$ https://lpdaac.usgs.gov/
} 
TABLE 1. Summary of the data used in this study.

\begin{tabular}{lccccl}
\hline \hline Product & Data used & Spatial resolution & Temporal resolution & Period & Reference \\
\hline VIs & MOD09A1 & $500 \mathrm{~m}$ & $8 \mathrm{~d}$ & $2000-2014$ & Vermote et al. (2002) \\
LST & MOD11A2 & $1,000 \mathrm{~m}$ & $8 \mathrm{~d}$ & $2000-2014$ & Wan et al. (2002) \\
Land cover & MCD12Q1 & $500 \mathrm{~m}$ & yearly & $2001-2012$ & Friedl et al. (2010) \\
DSI & MODIS ET/NDVI & $0.05^{\circ}$ & yearly & $2000-2011$ & Mu et al. (2013) \\
SPI & $\mathrm{P}$ & $1^{\circ}$ & yearly & $1949-2012$ & O'Loughlin et al. (2012) \\
PDSI & T, P & $2.5^{\circ}$ & yearly & $1850-2012$ & Dai et al. (2004), Dai (2011) \\
$T, P$ & CRU 3.2 & $0.5^{\circ}$ & monthly & $1901-2013$ & Harris et al. (2014) \\
\hline
\end{tabular}

Note:: VIs, Vegetation Indices; LST, Land Surface Temperature; DSI, Drought Severity Index; SPI, Standardized Precipitation Index; PDSI, Palmer Drought Severity Index; $T$, Temperature; $P$, Precipitation.

$$
\begin{gathered}
\text { EVI }=2.5 \times \frac{\rho_{\text {nir }}-\rho_{\text {red }}}{\rho_{\text {nir }}+6 \times \rho_{\text {red }}-7.5 \times \rho_{\text {blue }}+1} \\
\text { LSWI }=\frac{\rho_{\text {nir }}-\rho_{\text {swir }}}{\rho_{\text {nir }}+\rho_{\text {swir }}} \\
\text { NDSI }=\frac{\rho_{\text {green }}-\rho_{\text {swir } 1}}{\rho_{\text {green }}+\rho_{\text {swir } 1}}
\end{gathered}
$$

where $\rho_{\text {blue }}, \rho_{\text {green }}, \rho_{\text {red }}, \rho_{\text {nir }}$ and $\rho_{\text {swir }}$ are the surface reflectance for the blue, green, red, near-infrared, and shortwave-infrared bands, respectively.

The bad observations, including clouds, cloud shadows, and snow, were excluded to form a long-term time series vegetation index data set by using a two-step strategy. First, we used the data quality information from the quality control flag layer to extract the clouds and cloud shadows from each image. Second, we applied an additional restriction in which the pixels with a blue reflectance of $\geq 0.2$ were also labeled as cloudy (Xiao et al. 2005) (Appendix S1: Fig. S2). The snow cover pixels were also excluded using the NDSI and the nearinfrared (NIR) band (Hall et al. 2002), specifically NDSI $>0.40$ and NIR $>0.11$ (Xiao et al. 2005). All the pixels identified as cloud, cloud shadow, or snow covers were excluded. The gaps in time series vegetation index data due to bad quality observations were gap filled using the linear interpolation approach. When the continuous gaps contained no more than three consecutive points, the linear interpolation approach was used to gap fill the time series data. More than three consecutive missing observations were limited in our study area (temperate zone) as the effects of clouds and clouds shadows in the growing season are much less than in tropical regions (Zhang et al. 2015).

Time series land surface temperature (LST) data.-The Land Surface Temperature and Emissivity 8-D L3 Global $1 \mathrm{~km}$ product (MOD11A2) from 2000 to 2014 was used to calculate the nighttime LST-based thermal growing season in this study. The retrieval of LST has been improved by correcting noises from cloud contamination, zenith angle changes, and topographic differences; it agreed well with in situ-based LST, and the absolute bias of LST is $<1 \mathrm{~K}$ (Wan 2008). The digital number values (DN) from MOD11A2 were converted to LST with centigrade unit values based on the following formula: $\operatorname{LST}\left({ }^{\circ} \mathrm{C}\right)=\mathrm{DN} \times 0.02-273.15($ Wan 2008). The gaps in time series LST data were filled by using linear interpolation.

Annual land cover data.-The MODIS Land Cover Type Yearly L3 Global 500 m SIN Grid product (MCD12Q1) was used to identify the targeted area. This data set provides five global land cover classifications schemes from 2001 to 2012. The International Geosphere-Biosphere Programme (IGBP)-based global vegetation classification scheme was used in this study, which identifies 17 land cover classes globally (Friedl et al. 2010). According to the land cover data in 2010, Central Asia primarily consists of five land cover classes: grasslands (64\%), barren $(15 \%)$, shrublands $(10 \%)$, croplands $(7 \%)$, and water $(2 \%)$.

Climate data.-The air temperature and precipitation data were obtained from the University of East Anglia Climatic Research Unit (CRU) Time Series 3.2 data set (Harris et al. 2014). The CRU data set is derived from archives of climate station records, available at the British Atmospheric Data Centre website. ${ }^{10}$ This data set is monthly climate observations at $0.5^{\circ} \times 0.5^{\circ}$ spatial resolution, covering the period from 1901 to 2013.

Three drought indices data sets were used to illustrate the drying trend and relationship with grassland degradation and desertification in this study region, including MODIS-based Drought Severity Index (DSI, 20002011; Mu et al. 2013), the meteorological-based Standardized Precipitation Index (SPI, 2000-2012; McKee et al. 1993, O'Loughlin et al. 2012), and the Palmer Drought Severity Index (PDSI, 2000-2012; Palmer 1965, Dai et al. 2004, Dai 2011). The DSI data product is a remotely sensed index using MODIS terrestrial evapotranspiration (ET)/potential ET and MODIS NDVI data as primary inputs (Mu et al. 2013). This data set covers all vegetated land areas with $1-\mathrm{km}$ spatial

\footnotetext{
${ }^{10}$ http://badc.nerc.ac.uk/
} 
resolution at 8-d, monthly, and annual intervals over the period from 2000 to 2011. Annual DSI was used in this study, obtained from the Numerical Terra dynamic Simulation Group, University of Montana (Mu et al. 2013; data available online).$^{11}$ The SPI data is commonly used to monitor drought and anomalous wet period, and is calculated based only on the long-term precipitation record for a desired period (McKee et al. 1993). This data set includes the SPI at 3 months, half-year, and annual scales for global land surface from 1949 to 2012 with $1^{\circ} \times 1^{\circ}$ grids, obtained from Climate Data Guide (O'Loughlin et al. 2012; data available online). ${ }^{12}$ PDSI is the other reasonable index at quantifying long-term drought for global land surface from 1850 to 2012 with $2.5^{\circ} \times 2.5^{\circ}$ grids, which was also obtained from Climate Data Guide (Dai et al. 2004, Dai 2011; data available online). ${ }^{13}$ Monthly PDSI is estimated by readily available temperature and precipitation data (Palmer 1965).

\section{Methods}

In order to understand and detect the trend and process of grassland degradation and desertification in Central Asia, we developed a method that observes both state conversion (e.g., between grasslands and sparsely vegetated land) and gradual within-state change (e.g., greenness dynamics), thereby creating a desertification zone classification-based grassland degradation strategy. Fig. 2 provides a flow chart illustrating the methodology and workflow used in this study.

Determination of targeted area by excluding croplands and forests.-The evident human-induced land use changes (e.g., agricultural abandonment, urbanization) in this region would affect the analysis of grassland degradation and desertification based on vegetation index. The spatial distribution of IGBP-based land cover types in Central Asia from 2001 to 2012 (Appendix S1: Fig. S3) showed the large variation in spatial distribution of croplands. So a targeted area, only including grassland, barren or sparsely vegetated, and desert regions, will be helpful to exclude the disturbance from them. It was clearly defined by the combination of land cover data and additional masks. Specifically, three steps were conducted to identify the spatially explicit extent of targeted area. First, annual information of grasslands or barren or sparsely vegetated lands, based on the IGBP classification scheme from MCD12Q1 data, was extracted for each year. Second, we applied additional masks (including a water bodies mask and an integrated mask of croplands, forests, and wetlands) to eliminate potential errors in the classification process of

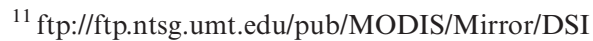

${ }^{12} \mathrm{https} / / /$ climatedataguide.ucar.edu/climate-data/standard ized-precipitation-index-spi

${ }^{13} \mathrm{https} / / /$ climatedataguide.ucar.edu/climate-data/palmerdrought-severity-index-pdsi
}

MCD12Q1 (Klein et al. 2012) and disturbances from other land cover types. A detailed description about the generation of masks is in Supplemental Materials. After applying these masks, annual refined grassland and sparsely vegetated land maps from 2001 to 2012 were generated. Last, the specific targeted area was ascertained by intersection of annual maps from 2001 to 2012 (Fig. 1b), most located in Kazakhstan.

Separation of grasslands and sparsely vegetated land.The conversions between grasslands and sparsely vegetated land were analyzed to determine the state conversions from 2000 to 2014. Clear distinction between grassland and sparsely vegetated land is essential for understanding how grassland degrades and converts into sparsely vegetated land from a land cover change perspective. Generally, from the view of vegetation coverage, grasslands have higher greenness than deserts, at the same time, the seasonal variation of EVI in deserts is smaller and more stable than that in grasslands (Appendix S1: Fig. S2).

Before analyzing vegetation variation and trend for the targeted area of Central Asia, we defined the LSTbased thermal growing season first for calculation of the mean EVI during the thermal growing season. Plants generally begin to grow when a stable temperature threshold is reached, in order to avoid damage from cold temperatures. By comparing the observational vegetation phenology data and the temporal profile of nighttime LST (Appendix S1: Fig. S2), we calculated the start and end dates of thermal growing season with nighttime LST above $0^{\circ} \mathrm{C}$ (LST0) in continuous three 8-d intervals for each year from 2000 to 2014 (Appendix S1: Fig. S4). The resultant maps of the start and end dates of LST0 were resampled to $500 \mathrm{~m}$ using the nearest neighbor interpolation method to be spatially consistent with the vegetation index maps from MOD09A1.

In this study, standard deviation (SD) of EVI during the LST0-based thermal growing season (SDEVI ${ }_{\mathrm{TGS}}$ ) was used as an indicator to identify grassland and sparsely vegetated land. Comparing the EVI curves of grassland and sparsely vegetated land in Central Asia, the fluctuation in EVI curve of sparsely vegetated land was less than that of grassland (Appendix S1: Fig. S2d-f). In other words, fluctuation in EVI curve decreased with the drop in vegetation coverage. Taking the year of 2010 as an example, we summarized the distributions of SDE$\mathrm{VI}_{\mathrm{TGS}}$ from random 10,000 pixels in 2010 for each IGBP-based vegetation type in Central Asia. Among all the vegetation types, barren or sparsely vegetated had the lowest SDEVI ${ }_{\mathrm{TGS}}$ (Appendix S1: Fig. S5). From Appendix S1: Fig. S5, the value of SDEVI ${ }_{\mathrm{TGS}}$ equal to 0.02 could help to separate Barren or sparsely vegetated from all the vegetation types, so we used 0.02 as the SDEVI $_{\text {TGS }}$ threshold to distinguish grasslands and sparsely vegetated lands in the study area (Appendix S1: Figs. S5, 3). 


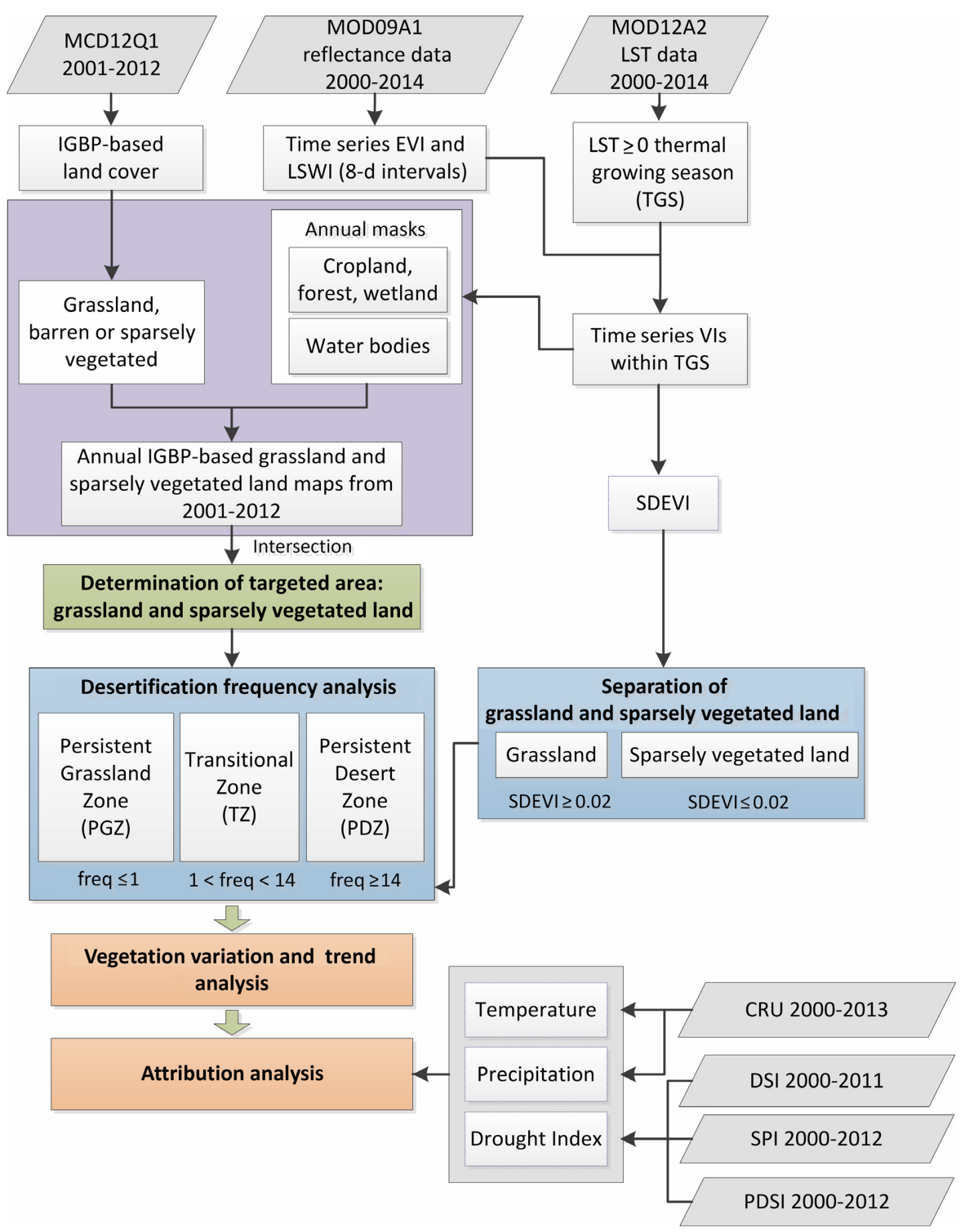

FIG. 2. Flow chart illustrating the data sources and methodology in this study. MCD12Q1, MOD09A1, and MOD12A2 are different MODIS datasets. IGBP, International Geosphere-Biosphere Programme; SDEVI, Standard Deviation of Enhanced Vegetation Index; CRU, Climatic Research Unit; DSI, Drought Severity Index; SPI, Standardized Precipitation Index; PDSI, Palmer Drought Severity Index.

Recognition of three desertification zones. - To evaluate state conversions, we explored the dynamics of classified vegetation types over time. Following the desertification theory (D'Odorico et al. 2013), three zones were identified: persistent grassland zone (PGZ), persistent desert zone (PDZ), and transitional zone (TZ). These zones were defined by the frequency of grassland vs. sparsely vegetated land classification at each pixel based on SDE$\mathrm{VI}_{\mathrm{TGS}}$ from 2000 to 2014 (Appendix S1: Fig. S6), with PGZ, PDZ, and TZ corresponding to classification as sparsely vegetated land $0-1 \mathrm{yr}$ (never or rarely),
14-15 yr (always or usually), and 2-13 yr (sometimes), respectively.

Vegetation variation and trend analysis within individual desertification zones. - To evaluate gradual vegetation change, we explored greenness trends over the time period. Within each desertification zone, we extracted the mean EVI during the LST0-based thermal growing season $\left(\mathrm{EVI}_{\mathrm{TGS}}\right)$ for each year from 2000 to 2014. Two approaches, the linear regression and Mann-Kendall test, were used for the statistical analysis. The linear 


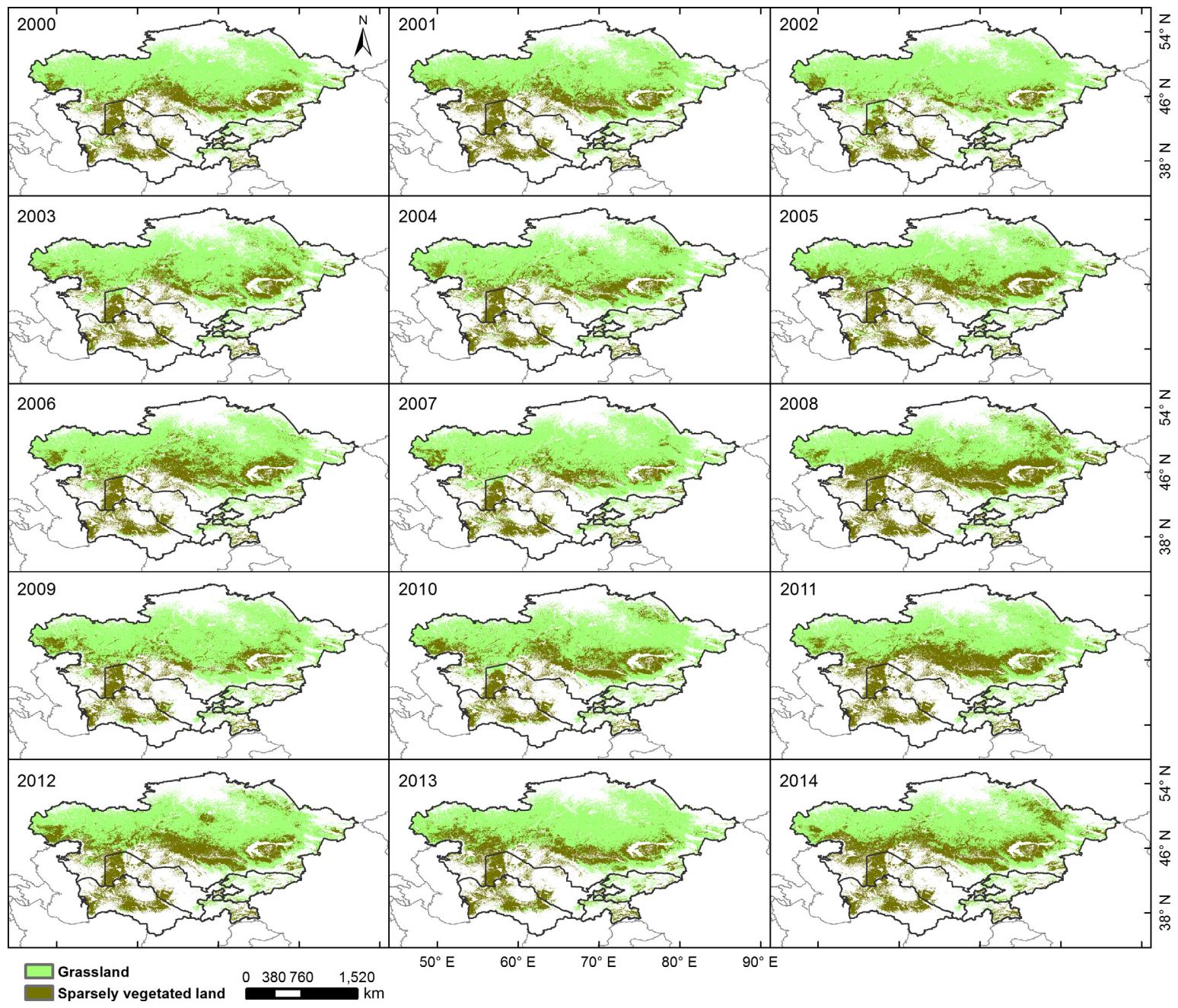

FIG. 3. Annual spatial distribution of $\mathrm{SDEVI}_{\mathrm{TGS}}$-derived grassland and sparsely vegetated land in targeted area of Central Asia

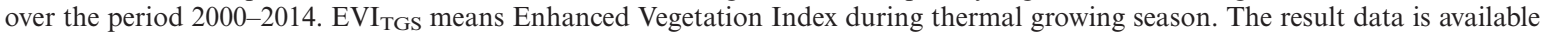
from https://doi.org/10.5061/dryad.12bd9.

regression calculated the slope of the linear least squares regression line fit to the inter-annual variation of the $\mathrm{EVI}_{\mathrm{TGS}}$ values. The statistical significance of $\mathrm{EVI}_{\mathrm{TGS}}$ change was mapped and assessed based on the two-tailed significance tests (Zhang et al. 2013). MannKendall trend test is a nonparametric test used to identify a trend in $\mathrm{EVI}_{\mathrm{TGS}}$, even if there is a seasonal component in the series (Fensholt et al. 2012, Zhang et al. 2016).

Climate change effects on grassland degradation and desertification.-To explore main driving factors for grassland degradation and desertification in this region, we performed correlation analysis between $\mathrm{SDEVI}_{\mathrm{TGS}}$ and different climate variables (precipitation and temperature) as well as drought indices (DSI, PDSI, and SPI). The relationships of spatially averaged SDEVI $_{\mathrm{TGS}}$ and climate factors were analyzed. The spatial distribution of correlations between $\mathrm{SDEVI}_{\mathrm{TGS}}$ and climate factors were also considered.

\section{Results}

Increasing conversion from grasslands to sparsely vegetated land from 2000 to 2014

Central Asia is primarily covered by grassland, mostly distributed in central Kazakhstan and adjacent with the sparsely vegetated land zone in the southern Kazakhstan (Fig. 3). The changes in SDEVI $\mathrm{TGS}_{\text {-indicated grassland }}$ area of Central Asia over the period 2000-2014 showed an evident decrease with a rate of $-0.14 \times 10^{5} \mathrm{~km}^{2} / \mathrm{yr}$ $(P=0.08$; Fig. $4 \mathrm{c})$. Grassland decreased by $12.5 \%$ from 2000 to 2014. Specially, the area of grassland in 2002 was the largest, followed by 2007 and 2009, while that in 2008 was the lowest. 


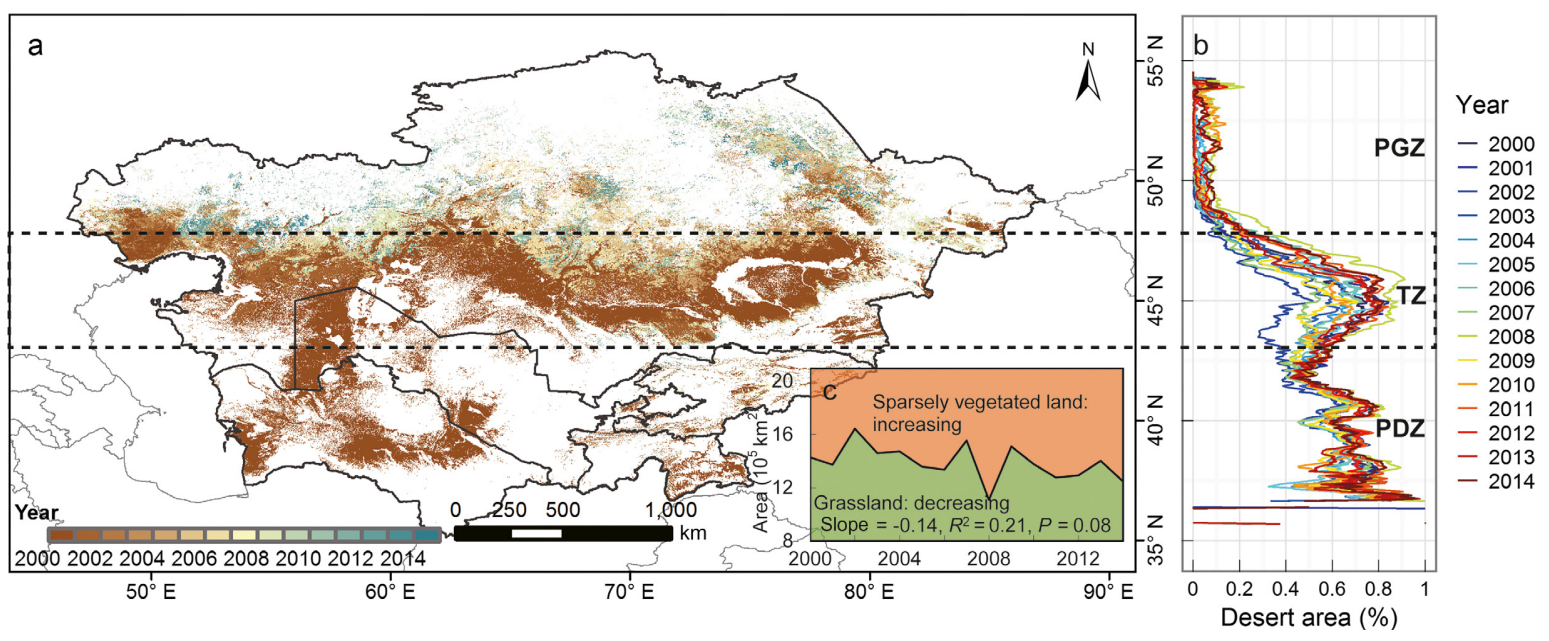

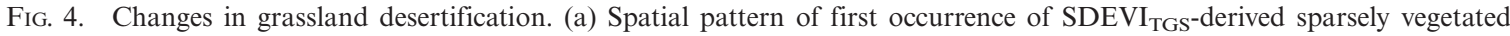
land for each pixel over the period 2000-2014; (b) distribution of SDEVI TGS -derived sparsely vegetated land area along latitude gradients in each year; (c) inter-annual variation of $\mathrm{SDEVI}_{\mathrm{TGS}}$-derived grassland and sparsely vegetated land areas. PGZ, TZ, and PDZ in panel $\mathrm{b}$ mean persistent grassland zone, transition zone, and persistent desert zone, respectively. EVI $\mathrm{TGS}_{\mathrm{TGS}}$ means Enhanced Vegetation Index during thermal growing season. The result data is available from https://doi.org/10.5061/dryad.12bd9.

The statistics in SDEVI $_{\mathrm{TGS}}$-indicated grassland and sparsely vegetated land areas by latitude (Fig. 4b) showed that the grassland area evidently decreased in Central Asia in the past $15 \mathrm{yr}$, especially within a latitude range of $43-48^{\circ} \mathrm{N}$. In addition, the first year with sparsely vegetated land occurrence over the period 2000-2014 gradually occurred from south to north in Central Asia (Fig. 4a), indicating the northward extension of desertification zone, which led to the large decrease in grasslands.

From the desertification zone classification, this region was mainly dominated by PGZ, accounted for $46 \%$; followed by TZ with $37 \%$; and the area of PDZ was the smallest, only $17 \%$ (Fig. 5). PGZ, TZ, and PDZ were distributed in Central Asia from north to south, which showed the gradually decreased vegetation cover from north to south (Fig. 5). This spatial pattern was consistent with that of the multi-year averaged $\mathrm{EVI}_{\mathrm{TGS}}$ in study area (Appendix S1: Fig. S7), with higher EVI $_{\text {TGS }}$ values observed in PGZ (dense vegetated) and lower $\mathrm{EVI}_{\mathrm{TGS}}$ values observed in PDZ (sparse vegetated). The distribution of PGZ and TZ presented continuous strips from west to east. Fig. $4 \mathrm{~b}$ show that there was evident decreases in grasslands in the TZ. Therefore, the TZ, the fragile and sensitive ecotone, was identified as one important hotspot in Central Asia that was vulnerable for desertification and determined the direction of desertification.

\section{Gradual within-state changes in different zones}

We conducted a trend analysis by fitting a linear trend of the average annual $\mathrm{EVI}_{\mathrm{TGS}}$ in the whole study area and different zones mentioned above (Fig. 6). The
$\mathrm{EVI}_{\mathrm{TGS}}$ of study area over the period 2000-2014 showed an evident decreasing trend at a rate of -0.0014 $\left(R^{2}=0.45, P=0.006, n=15\right)$. In terms of the three zones, there were consistent trends of $\mathrm{EVI}_{\mathrm{TGS}}$ between in PGZ and TZ $(R=0.85, P<0.001)$, which showed significant decreases in the order of $-0.0021\left(R^{2}=0.49\right.$, $P=0.004, n=15)$ and $-0.001\left(R^{2}=0.34, P=0.02\right.$, $n=15$ ), respectively. The EVI $\mathrm{TGS}_{\mathrm{T}}$ in PDZ showed an insignificant and fluctuating change $\left(R^{2}=0.12, P=\right.$ $0.20, n=15$ ).

Both the linear regression and Mann-Kendall methods revealed similar spatial patterns of $\mathrm{EVI}_{\mathrm{TGS}}$ trends in the study area (Fig. 7). The linear regression analysis showed a decreasing trend of $\mathrm{EVI}_{\mathrm{TGS}}$ in almost all parts of the targeted area $(90 \%)$, and the decreasing trend was significant in $25 \%(36 \%)$ of the targeted area with a significance level of $P<0.05(P<0.1 ;$ Fig. 7a, Table 2$)$. The majority of significant decreases in $\mathrm{EVI}_{\mathrm{TGS}}$ mainly occurred in the northern part of Kazakhstan with large swaths, which was the mainly region of PGZ, with $67 \%$ $(64 \%)$ of significant decreases at significance level of $P<0.05 \quad(P<0.1)$ distributed in PGZ (Fig. 7a, Table 2). The area with an increasing trend of $\mathrm{EVI}_{\mathrm{TGS}}$ was very limited, only $10 \%$ of the targeted area (Table 2), mainly distributed in the eastern part of Central Asia; and the increasing trend with a significance level of $P<0.1$ was $<1 \%$ (Table 2) of the targeted area. The Mann-Kendall-based trend analysis also showed a similar spatial pattern of $\mathrm{EVI}_{\mathrm{TGS}}$ change in this region (Fig. 7b, Table 2). The area with significant decreasing in $\mathrm{EVI}_{\mathrm{TGS}}$ within PGZ means that this region experienced gradual grassland degradation and in risk for desertification, which was the second hotspot identified in Central Asia in this study. 


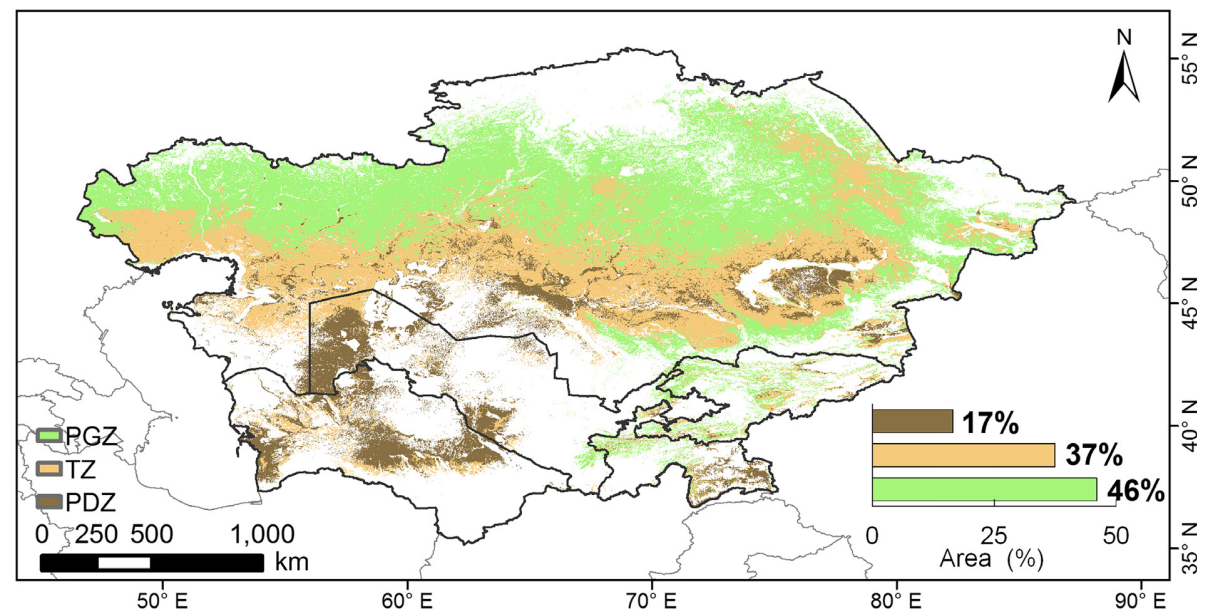

FIG. 5. Spatial distribution of persistent grassland zone (PGZ), transition zone (TZ), and persistent desert zone (PDZ). The inset shows the area percentages of different zones. The result data is available from https://doi.org/10.5061/dryad.12bd9.

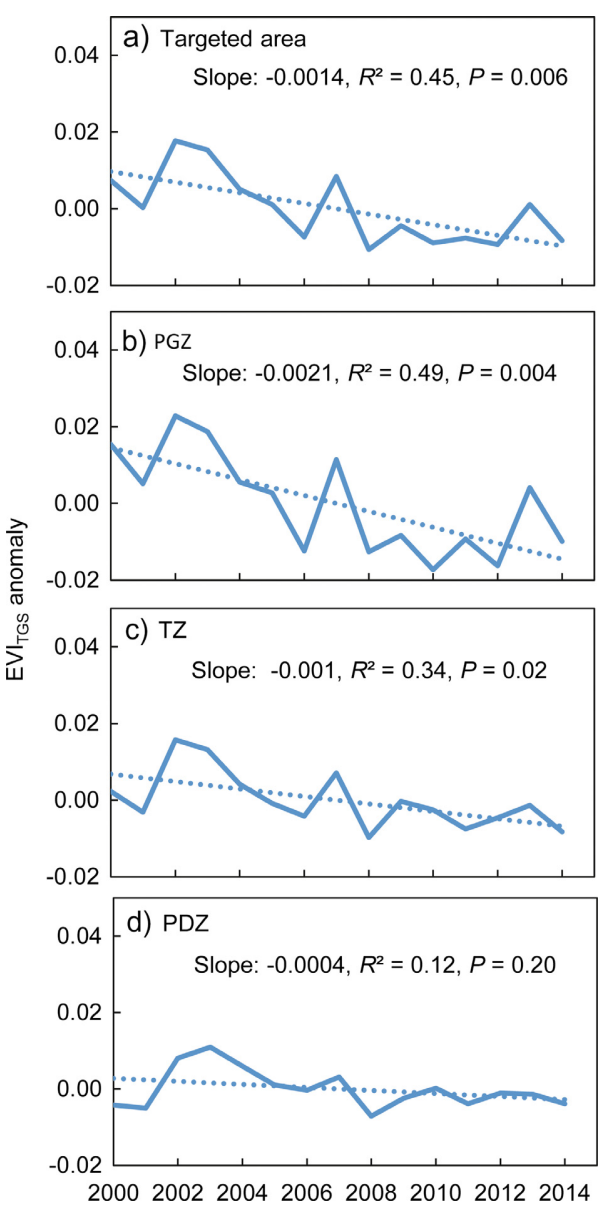

FIG. 6. Trend analyses in averaged EVI $\mathrm{EGS}_{\mathrm{TGS}}$ anomalies in (a) targeted area, (b) persistent grassland zone (PGZ), (c) transition zone (TZ), and (d) persistent desert zone (PDZ) of Central Asia over the period 2000-2014. The solid lines are the values, the dotted lines are the regression. EVI TGS means Enhanced Vegetation Index during thermal growing season.

\section{Effects of droughts on grassland degradation and desertification}

Despite different data sources and spatial resolutions, the three drought indices (PDSI, SPI, and DSI) were highly correlated (correlation coefficients between each other were larger than 0.73 , and all of $P<0.05$ ), and showed similar decreasing trends over the targeted area of Central Asia since 2000 (Fig. 8). There were significant decreases in PDSI and DSI with rates of -0.10 $(P=0.04)$ and $-0.13(P=0.009)$, respectively, while the decreasing trend of SPI was not significant (Fig. 8f-h). Although both precipitation and temperature showed decreasing trends over the same period (precipitation, slope $=-2.86 \mathrm{~mm} / \mathrm{yr}, P=0.16 ;$ temperature, slope $=$ $-0.06{ }^{\circ} \mathrm{C} / \mathrm{yr}, P=0.17$; Fig. $8 \mathrm{i}, \mathrm{j}$ ), the precipitation was the main driver inducing drought intensification in Central Asia according to the correlation between different drought indices and precipitation and temperature (Appendix S1: Table S1). It is noteworthy that the mean temperature anomaly during 1997-2012 was evidently larger than that during 1950-1996, showing the recent 16 years from 1997 to 2012 was the warmest period in the last 60 years (Fig. 8j). At the spatial scale, the drying trends from three drought indices were widespread across this region, northern region showing a significant negative trend $(P<0.05$; Fig. $8 \mathrm{a}-\mathrm{c})$. Precipitation also showed similar decreasing trend with these drought indices at spatial pattern (Fig. 8d), while temperature showed an insignificant increase in the northwestern part and decease in the eastern part, which was evidently different with the spatial patterns of the drought indices trends (Fig. 8e). It showed that precipitation was the key factor for controlling the drought in this region.

The relationships of $\mathrm{EVI}_{\mathrm{TGS}}$ and three drought indices (DSI, PDSI, and SPI) as well as two climate variables 


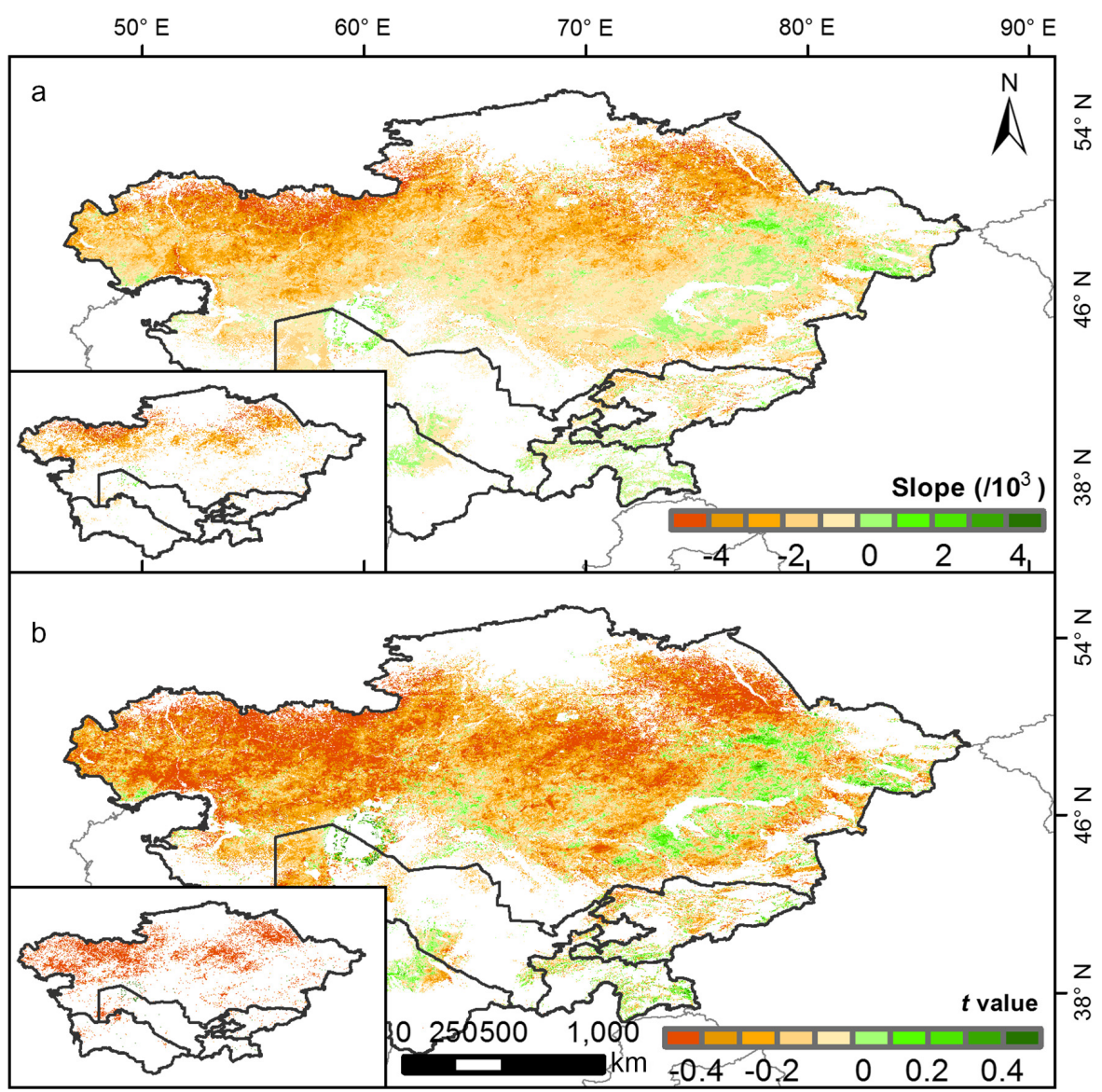

FIG. 7. Spatial patterns of (a) linear regression trend and (b) Mann-Kendall trend of Enhanced Vegetation Index during thermal growing season $\left(\mathrm{EVI}_{\mathrm{TGS}}\right.$ ) in targeted area of Central Asia over the period 2000-2014. The $t$ value is Kendall's tau coefficient. Slope in panel a is calculated as linear regression coefficient. The insets show the region with statistical significance at 0.05 level. The result data is available from https://doi.org/10.5061/dryad.12bd9.

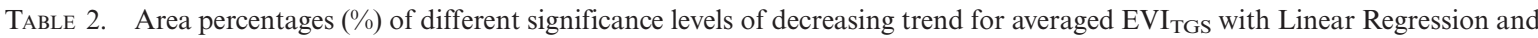
Mann-Kendall methods in the whole study area and the persistent grassland zone (PGZ) in Central Asia over the period 20002014.

\begin{tabular}{|c|c|c|c|c|}
\hline \multirow[b]{2}{*}{ Trend } & \multicolumn{2}{|c|}{ Linear regression } & \multicolumn{2}{|c|}{ Mann-Kendall } \\
\hline & Targeted area $(\%)$ & PGZ $(\%)$ & Targeted area $(\%)$ & PGZ $(\%)$ \\
\hline Trend $>0$ and $P<0.05$ & 0.44 & 0.15 & 0.38 & 0.13 \\
\hline Trend $>0$ and $P<0.1$ & 0.69 & 0.28 & 0.60 & 0.24 \\
\hline Trend $>0$ & 10.21 & 6.02 & 11.16 & 6.04 \\
\hline Trend $<0$ and $P<0.05$ & 24.89 & 36.39 & 22.85 & 32.52 \\
\hline Trend $<0$ and $P<0.1$ & 35.95 & 49.87 & 33.45 & 46.04 \\
\hline Trend $<0$ & 89.79 & 93.98 & 88.84 & 93.96 \\
\hline $\begin{array}{l}\text { Ratio of the area of trend }<0 \text { and } P<0.05 \text { in } \\
\text { PGZ to that in targeted area }\end{array}$ & 67.24 & & 65.45 & \\
\hline $\begin{array}{l}\text { Ratio of the area of trend }<0 \text { and } P<0.1 \text { in } \\
\text { PGZ to that in targeted area }\end{array}$ & 63.80 & & 63.30 & \\
\hline
\end{tabular}

(annual precipitation and mean temperature) were examined using correlation analysis. From the inter-annual variations, there were strong relationships between $\mathrm{EVI}_{\mathrm{TGS}}$ and the three drought indices with $P<0.01$
(Fig. 9a). Although $\mathrm{EVI}_{\mathrm{TGS}}$ was significantly related with annual precipitation $(P=0.01)$, the significance level was smaller than those with three drought indices (Fig. 9b). Whereas, the $\mathrm{EVI}_{\mathrm{TGS}}$ was not significantly related to 

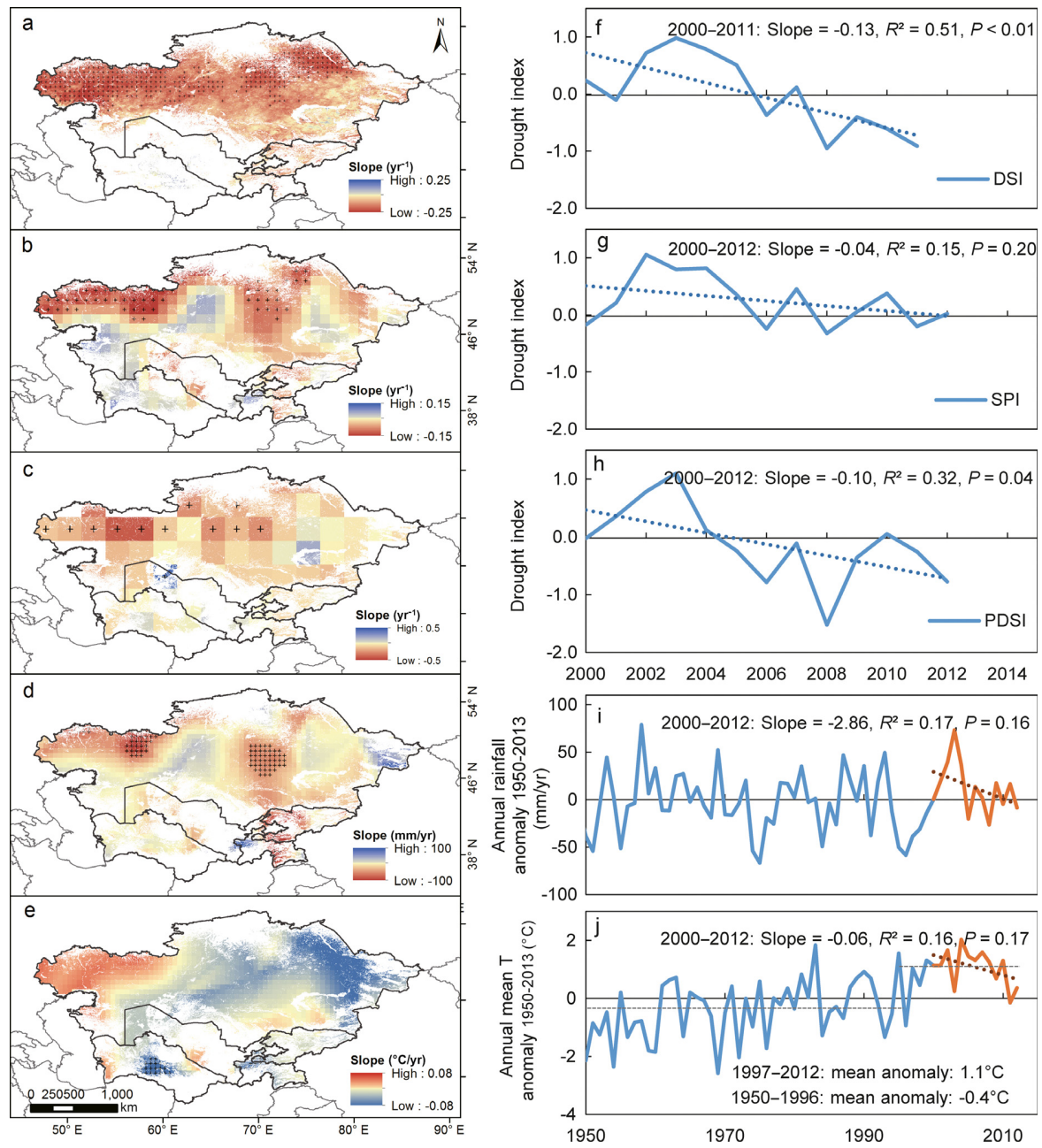

FIG. 8. Trends and variations in three drought indices, precipitation, and temperature. Left column shows spatial patterns of linear regression slope of (a) Drought Severity Index (DSI) from 2000 to 2011, (b) Standardized Precipitation Index (SPI) from 2000 to 2012, (c) Palmer Drought Severity Index (PDSI) from 2000 to 2012, (d) annual precipitation from 2000 to 2013 , and (e) annual mean temperature from 2000 to 2013. In each map, regions with plus symbol have a linear trend that is statistically significant at $P<0.05$. Right column shows the anomalies in (f) DSI from 2000 to 2011, (g) PDSI from 2000 to 2012, (h) SPI from 2000 to 2012, (i) precipitation from 1950 to 2013, and (j) mean temperature from 1950 to 2013 in targeted area of Central Asia.

annual mean temperature $(P=0.42$; Fig. 9 c). The spatial correlations between $\mathrm{EVI}_{\mathrm{TGS}}$ and drought indices, precipitation, and temperature showed the pattern of spatial correlations between $\mathrm{EVI}_{\mathrm{TGS}}$ and SPI agreed well with that between EVI $_{\mathrm{TGS}}$ and PDSI, as well as precipitation (Fig. 10a-c); while the pattern of spatial correlations between $\mathrm{EVI}_{\mathrm{TGS}}$ and temperature was different (Fig. 10d). The spatial correlations with a significance level of $P<0.05$ between $\mathrm{EVI}_{\mathrm{TGS}}$ and two drought indices as well as precipitation were generally located in northwestern and southern parts of targeted area (Fig. 10a-c). The area with significant spatial correlation between $\mathrm{EVI}_{\mathrm{TGS}}$ and temperature was limited in the northeastern part (Fig. 10d).

\section{Discussion}

On the whole, this study provided observational evidence for a widespread grassland degradation and desertification over the past 15 years in Central Asia through the examination of two processes (state conversion and gradual vegetation change). Specifically, the traditional methods based on trend analysis of vegetation indices alone could have overlooked the sparsely vegetation regions, which determined the direction of grassland desertification (Appendix S1: Fig. S1). The transitional ecotone, dominated by barren or sparsely vegetated land, was the unstable region between grasslands and deserts under the effects of external disturbance 

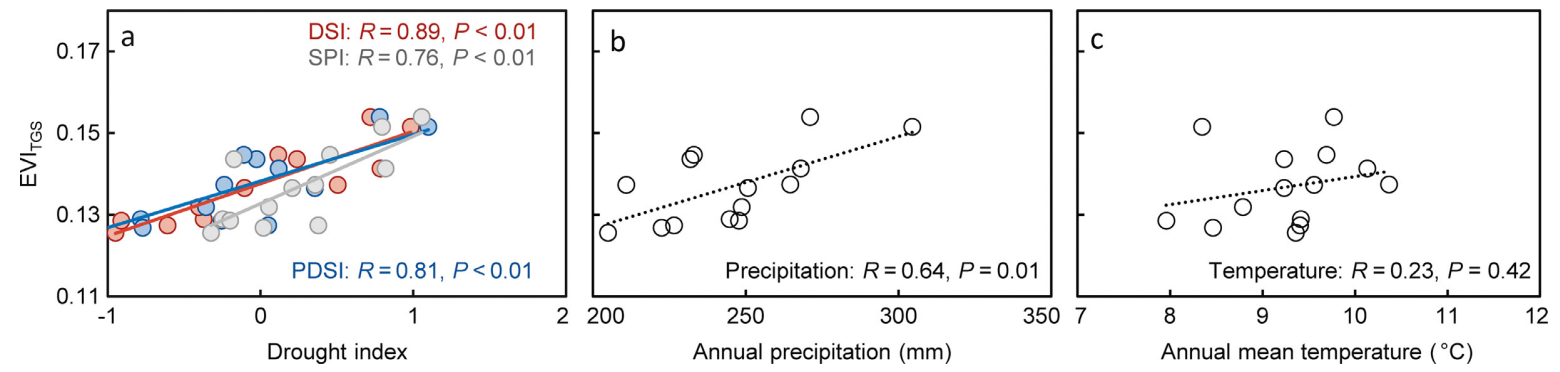

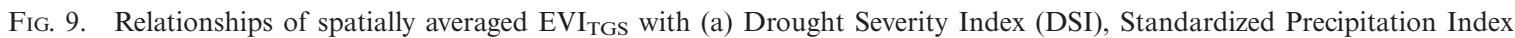
(SPI), Palmer Drought Severity Index (PDSI), (b) annual precipitation, and (c) annual mean temperature in targeted area of Cen-

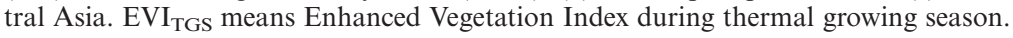

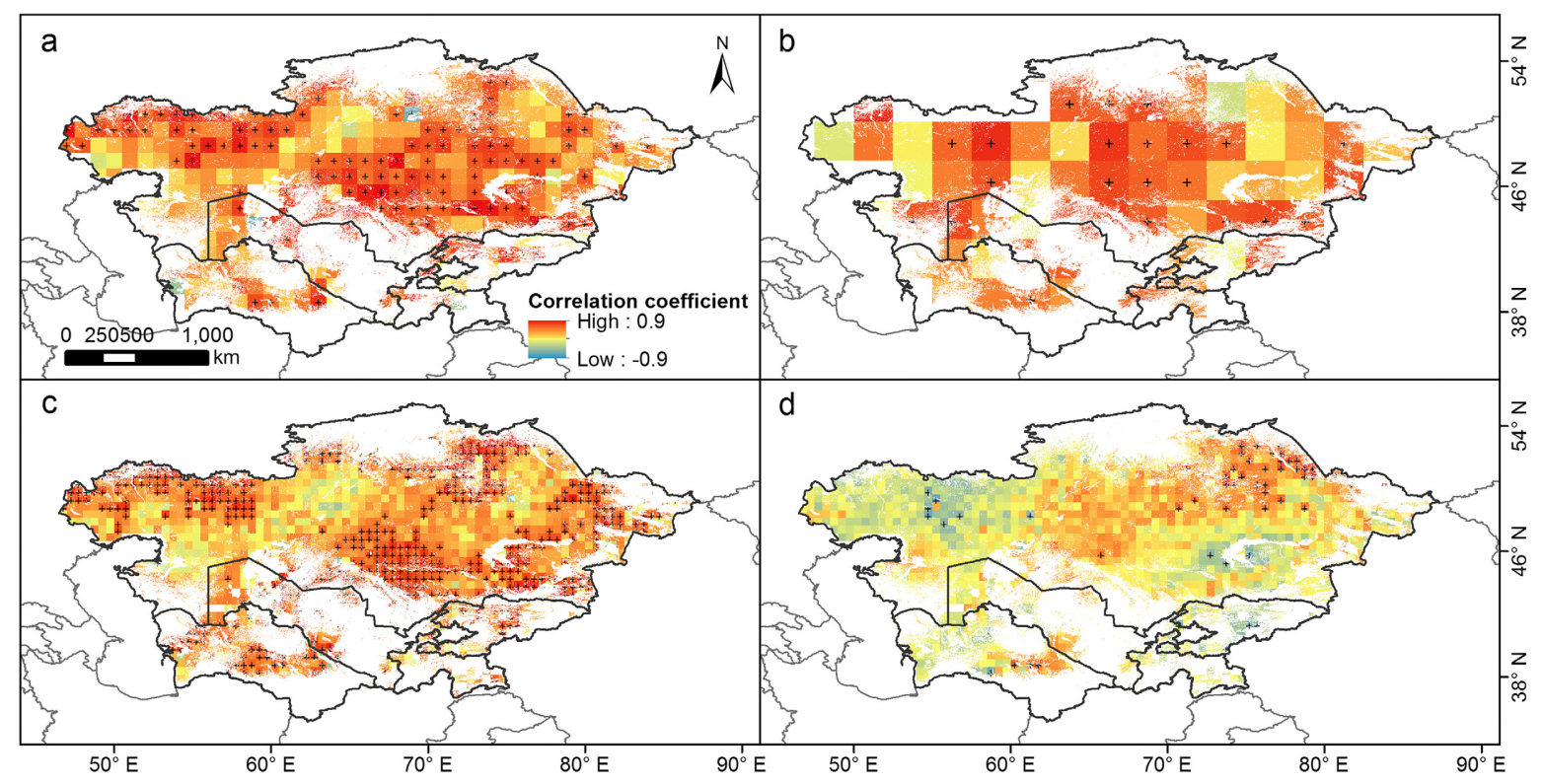

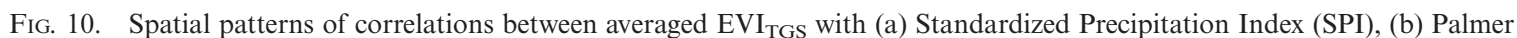
Drought Severity Index (PDSI), (c) annual precipitation, and (d) annual mean temperature in targeted area of Central Asia. In each map, regions with plus symbol have a linear trend that is statistically significant at $P<0.05$. EVI $\mathrm{TGS}_{\mathrm{TG}}$ means Enhanced Vegetation Index during thermal growing season.

(D'Odorico et al. 2013). The area of SDEVI $\mathrm{TGS}$-based sparsely vegetated land evidently increased in $\mathrm{TZ}$ of Central Asia in last 15 years, showing increasing unstable area and risks to desertification. The identification of the TZ in this study could help to guide the potential ecological restoration projects. The second hotspot identified in this study was located in the north of Kazakhstan in PGZ, which experienced an evident browning trend and agreed with previous studies (Mohammat et al. 2013, de Beurs et al. 2015, Zhou et al. 2015). The statistical analyses using both linear regression and the Mann-Kendall test guaranteed the reliability of the trend analyses in individual desertification zones.

Another advance in technical perspective of this study was definition of EVI during thermal growing season. Annual or seasonal vegetation index was generally used in previous studies for vegetation change analysis in Central Asia (Piao et al. 2011b, Mohammat et al. 2013, Zhou et al. 2015). However, the study region is across a large latitudinal range from $35^{\circ}$ to $57^{\circ} \mathrm{N}$, displaying a transition from cold temperate zone, temperate zone to subtropical zone. Large differences in vegetation growth phases exist from north to south. Therefore, it is unsuitable to define vegetation growing season with same period for the whole region, such as from April to October (Mohammat et al. 2013, Zhou et al. 2015). If the invariable length of growing season is considered in this region, such as April as starting point of vegetation growth, the early and short-lived vegetation would be neglected (Appendix S1: Fig. S2e). Therefore, identification of vegetation growing season in Central Asia needs be more careful. In this study, a thermal growing season 
defined by using daily surface temperature (Zhang et al. 2015) provided a better option for tracking vegetation dynamics in a spatially and temporally consistent way, and this method could be extended to other studies about regional vegetation changes.

In addition, the targeted area (only including grasslands, barren or sparsely vegetated, and deserts) for the grassland degradation and desertification observations was identified in this study to avoid disturbance from drastic land use changes (e.g., agricultural cultivation, urbanization). For example, the reasons for vegetation browning in the northwest of Kazakhstan were complex. Zhou et al. (2015) demonstrated that vegetation growth was significantly affected by precipitation in this region; while de Beurs et al. (2015) attributed the browning to a combination of drought and increasing fallow periods (or ongoing agricultural abandonment). One important reason for difficulty in attribution analysis of grassland degradation and desertification could be from the mixture of landscape changes in the region. Specifically, previous studies analyzed changes in vegetation greenness and their trends in the entire Central Asia, and did not separate effects of human-induced land cover conversions (e.g., abandonment, urbanization) or simply used static land cover information in a given period (Gessner et al. 2013, Mohammat et al. 2013, de Beurs et al. 2015, Zhou et al. 2015). In fact, vegetation browning caused by land cover changes (e.g., cropland abandonment, fallows, urbanization) would induce a feint of land degradation and desertification. Therefore, exclusion of land use change effects is of importance to better understand the process and drivers of grassland degradation and desertification in Central Asia; otherwise, the phenomenon of grassland degradation and desertification would be a mixture with land cover and land use change information.

Based on the refined targeted area in this study, we found observed $\mathrm{EVI}_{\mathrm{TGS}}$ change was principally attributable to persistent drought $(P<0.01$, Fig. 9a), comparing to influences of temperature. The high desertification in 2008 (Fig. 4) was consistent with the trough in drought index (Fig. 8f-h), which also indicated the sensitivity of grassland degradation to droughts. While this study focused on process of grassland degradation and desertification and its attribution to climate factors, the effects of socioeconomic factors, e.g., livestock density, land use change, were not considered in this study (Wright et al. 2012); which could need to be investigated in the future, in order to improve the understanding on process and drivers of grassland degradation and desertification in the region.

\section{Conclusions}

Knowledge of process of grassland degradation and desertification against the background of global climate change is essential for taking early action to prevent the increase in desertification in Central Asia. In this study, we carried out satellite data based analysis and provided a comprehensive picture for grassland degradation and desertification in Central Asia from 2000 to 2014, considering both state conversion and within-state gradual change. This new analyses on the grassland degradation and desertification also contributed to improved understanding of its drivers.

Our analysis provided three key insights into grassland degradation and desertification in Central Asia. First, the state conversion analysis showed that grassland degradation increased from 2000 to 2014, and desertification was gradually expanding northward. Secondly, our results clearly identified sensitive and fragile regions, one was the region in the $\mathrm{TZ}$ with higher sparsely vegetated land frequency in southern Kazakhstan, and the other was the significant browning region within the PGZ in northern Kazakhstan. The identification of these hotspots in this study can help decision makers to effectively mitigate desertification in Central Asia; for example, it can guide grazing activities, water extraction, and other anthropogenic activities. The desertification zone classification-based grassland degradation strategy, by integrating abrupt state conversion information and gradual within-state dynamics, can also be used to detect grassland degradation and desertification in the other dryland regions. Last but not least, grassland degradation and desertification was largely linked with persistent droughts in Central Asia. Given the projected increase in drought and warming (Huang et al. 2015), grassland degradation and desertification is expected to exacerbate in Central Asia in the future. Therefore, the treatment of the desertification hotspots should be paid more attention to avoid potential aggravation of desertification.

\section{ACKNOWLEDGMENTS}

This study was supported by research grants from the National Institutes of Health NIAID (1R01AI101028-01-A2), Key Research Program of Frontier Sciences, Chinese Academy of Sciences (QYZDB-SSW-DQC005), and "Thousand Youth Talents Plan". C. Biradar and R. J. Thomas acknowledge the support of the CGIAR Dryland Systems program.

\section{Literature Cited}

Alibakhshi, S., T. Groen, M. Rautiainen, and B. Naimi. 2017. Remotely-sensed early warning signals of a critical transition in a wetland ecosystem. Remote Sensing 9:352.

Dai, A. 2011. Characteristics and trends in various forms of the Palmer Drought Severity Index during 1900-2008. Journal of Geophysical Research: Atmospheres 116:D12115.

Dai, A., K. E. Trenberth, and T. Qian. 2004. A global dataset of Palmer Drought Severity Index for 1870-2002: Relationship with soil moisture and effects of surface warming. Journal of Hydrometeorology 5:1117-1130.

de Beurs, K. M., G. M. Henebry, B. C. Owsley, and I. Sokolik. 2015. Using multiple remote sensing perspectives to identify and attribute land surface dynamics in Central Asia 20012013. Remote Sensing of Environment 170:48-61. 
D’Odorico, P., K. Caylor, G. S. Okin, and T. M. Scanlon. 2007. On soil moisture-vegetation feedbacks and their possible effects on the dynamics of dryland ecosystems. Journal of Geophysical Research: Biogeosciences 112:G04010.

D'Odorico, P., A. Bhattachan, K. F. Davis, S. Ravi, and C. W. Runyan. 2013. Global desertification: Drivers and feedbacks. Advances in Water Resources 51:326-344.

Eckert, S., F. Hüsler, H. Liniger, and E. Hodel. 2015. Trend analysis of MODIS NDVI time series for detecting land degradation and regeneration in Mongolia. Journal of Arid Environments 113:16-28.

Fensholt, R., et al. 2012. Greenness in semi-arid areas across the globe 1981-2007 - an Earth Observing Satellite based analysis of trends and drivers. Remote Sensing of Environment 121:144-158.

Friedl, M. A., D. Sulla-Menashe, B. Tan, A. Schneider, N. Ramankutty, A. Sibley, and X. Huang. 2010. MODIS Collection 5 global land cover: Algorithm refinements and characterization of new datasets. Remote Sensing of Environment 114:168-182.

Gessner, U., V. Naeimi, I. Klein, C. Kuenzer, D. Klein, and S. Dech. 2013. The relationship between precipitation anomalies and satellite-derived vegetation activity in Central Asia. Global and Planetary Change 110:74-87.

Gong, Z., K. Kawamura, N. Ishikawa, M. Goto, T. Wulan, D. Alateng, T. Yin, and Y. Ito. 2015. MODIS normalized difference vegetation index (NDVI) and vegetation phenology dynamics in the Inner Mongolia grassland. Solid Earth 6:1185-1194.

Hall, D. K., G. A. Riggs, V. V. Salomonson, N. E. DiGirolamo, and K. J. Bayr. 2002. MODIS snow-cover products. Remote Sensing of Environment 83:181-194.

Harris, I., P. Jones, T. Osborn, and D. Lister. 2014. Updated high-resolution grids of monthly climatic observations - the CRU TS3.10 dataset. International Journal of Climatology 34:623-642.

Holling, C. 1973. Resilience and stability of ecological systems. Annual Review of Ecology and Systematics 4:1-23.

Hu, G., H. Liu, Y. Yin, and Z. Song. 2016. The role of legumes in plant community succession of degraded grasslands in Northern China. Land Degradation \& Development 27:366372.

Huang, J., H. Yu, X. Guan, G. Wang, and R. Guo. 2015. Accelerated dryland expansion under climate change. Nature Climate Change 6:166-171.

Huete, A. R., H. Q. Liu, K. Batchily, and W. vanLeeuwen. 1997. A comparison of vegetation indices global set of TM images for EOS-MODIS. Remote Sensing of Environment 59:440-451.

Huete, A., K. Didan, T. Miura, E. P. Rodriguez, X. Gao, and L. G. Ferreira. 2002. Overview of the radiometric and biophysical performance of the MODIS vegetation indices. Remote Sensing of Environment 83:195-213.

Jeong, S.-J., C.-H. Ho, M. E. Brown, J.-S. Kug, and S. Piao. 2011. Browning in desert boundaries in Asia in recent decades. Journal of Geophysical Research: Atmospheres 116: D02103.

Karnieli, A., U. Gilad, M. Ponzet, T. Svoray, R. Mirzadinov, and O. Fedorina. 2008. Assessing land-cover change and degradation in the Central Asian deserts using satellite image processing and geostatistical methods. Journal of Arid Environments 72:2093-2105.

Klein, I., U. Gessner, and C. Kuenzer. 2012. Regional land cover mapping and change detection in Central Asia using MODIS time-series. Applied Geography 35:219-234.

Klein, I., U. Gessner, and C. Künzer. 2014. Generation of Up to Date Land Cover Maps for Central Asia. Pages 329-346 in
L. Mueller, A. Saparov, and G. Lischeid, editors. Novel measurement and assessment tools for monitoring and management of land and water resources in agricultural landscapes of central Asia. Springer International Publishing, Cham.

Li, J., et al. 2013. Monitoring and analysis of grassland desertification dynamics using Landsat images in Ningxia, China. Remote Sensing of Environment 138:19-26.

Li, Z., Y. Chen, W. Li, H. Deng, and G. Fang. 2015. Potential impacts of climate change on vegetation dynamics in Central Asia. Journal of Geophysical Research: Atmospheres 120:12345-12356.

Lin, L., Y. Li, X. Xu, F. Zhang, Y. Du, S. Liu, X. Guo, and G. Cao. 2015. Predicting parameters of degradation succession processes of Tibetan Kobresia grasslands. Solid Earth 6:1237-1246

Lioubimtseva, E., and G. Henebry. 2009. Climate and environmental change in arid Central Asia: Impacts, vulnerability, and adaptations. Journal of Arid Environments 73:963-977.

Loboda, T. V., L. Giglio, L. Boschetti, and C. O. Justice. 2012. Regional fire monitoring and characterization using global NASA MODIS fire products in dry lands of Central Asia. Frontiers of Earth Science 6:196-205.

Maki, M., M. Ishiahra, and M. Tamura. 2004. Estimation of leaf water status to monitor the risk of forest fires by using remotely sensed data. Remote Sensing of Environment 90:441-450.

McKee, T. B., N. J. Doesken, and J. Kleist. 1993. The relationship of drought frequency and duration to time scales. Pages 179-183 in Proceedings of the 8th Conference on Applied Climatology. American Meteorological Society, Boston, Massachusetts, USA

Mohammat, A., X. Wang, X. Xu, L. Peng, Y. Yang, X. Zhang, R. B. Myneni, and S. Piao. 2013. Drought and spring cooling induced recent decrease in vegetation growth in Inner Asia. Agricultural and Forest Meteorology 178-179:21-30.

Mu, Q., M. Zhao, J. S. Kimball, N. G. McDowell, and S. W. Running. 2013. A remotely sensed global terrestrial Drought Severity Index. Bulletin of the American Meteorological Society 94:83-98.

O'Loughlin, J., F. D. W. Witmer, A. M. Linke, A. Laing, A. Gettelman, and J. Dudhia. 2012. Climate variability and conflict risk in East Africa, 1990-2009. Proceedings of the National Academy of Sciences USA 109:18344-18349.

Palmer, W. C. 1965. Meteorological drought. US Department of Commerce, Weather Bureau, Washington, D.C., USA.

Pereira, P., A. Cerdà, A. J. Lopez, L. M. Zavala, J. MataixSolera, V. Arcenegui, I. Misiune, S. Keesstra, and A. Novara. 2016. Short-term vegetation recovery after a grassland fire in Lithuania: The effects of fire severity, slope position and aspect. Land Degradation \& Development 27:1523-1534.

Piao, S., M. Cui, A. Chen, X. Wang, P. Ciais, J. Liu, and Y. Tang. 2011a. Altitude and temperature dependence of change in the spring vegetation green-up date from 1982 to 2006 in the Qinghai-Xizang Plateau. Agricultural and Forest Meteorology 151:1599-1608.

Piao, S., X. Wang, P. Ciais, B. Zhu, T. Wang, and J. Liu. $2011 b$. Changes in satellite-derived vegetation growth trend in temperate and boreal Eurasia from 1982 to 2006. Global Change Biology 17:3228-3239.

Seddon, A. W. R., M. Macias-Fauria, P. R. Long, D. Benz, and K. J. Willis. 2016. Sensitivity of global terrestrial ecosystems to climate variability. Nature 531:229-232.

Sternberg, T., H. Rueff, and N. Middleton. 2015. Contraction of the Gobi desert, 2000-2012. Remote Sensing 7:1346-1358.

Tucker, C. J., H. E. Dregne, and W. W. Newcomb. 1991. Expansion and contraction of the Sahara desert from 1980 to 1990. Science 253:299-300. 
Vermote, E., and A. Vermeulen. 1999. Atmospheric correction algorithm: spectral reflectances (MOD09). ATBD version 4. http://dratmos.geog.umd.edu/files/pdf/atbd_mod09.pdf

Vermote, E. F., N. Z. El Saleous, and C. O. Justice. 2002. Atmospheric correction of MODIS data in the visible to middle infrared: first results. Remote Sensing of Environment 83:97-111.

Wan, Z. M. 2008. New refinements and validation of the MODIS Land-Surface Temperature/Emissivity products. Remote Sensing of Environment 112:59-74.

Wan, Z., Y. Zhang, Q. Zhang, and Z. Li. 2002. Validation of the land-surface temperature products retrieved from Terra Moderate Resolution Imaging Spectroradiometer data. Remote Sensing of Environment 83:163-180.

Wessels, K., F. Van Den Bergh, and R. Scholes. 2012. Limits to detectability of land degradation by trend analysis of vegetation index data. Remote Sensing of Environment 125:10-22.

Wright, C. K., K. M. de Beurs, and G. M. Henebry. 2012. Combined analysis of land cover change and NDVI trends in the Northern Eurasian grain belt. Frontiers of Earth Science $6: 177-187$.

Xi, X., and I. N. Sokolik. 2015. Dust interannual variability and trend in Central Asia from 2000 to 2014 and their climatic linkages. Journal of Geophysical Research: Atmospheres 120:12175-12197.

Xiao, X., S. Boles, S. Frolking, W. Salas, B. Moore, C. Li, L. He, and R. Zhao. 2002. Landscape-scale characterization of cropland in China using Vegetation and landsat TM images. International Journal of Remote Sensing 23:3579-3594.
Xiao, X., B. Braswell, Q. Zhang, S. Boles, S. Frolking, and B. Moore Iii. 2003. Sensitivity of vegetation indices to atmospheric aerosols: continental-scale observations in Northern Asia. Remote Sensing of Environment 84:385-392.

Xiao, X., S. Boles, J. Liu, D. Zhuang, S. Frolking, C. Li, W. Salas, and B. Moore Iii. 2005. Mapping paddy rice agriculture in southern China using multi-temporal MODIS images. Remote Sensing of Environment 95:480-492.

Zhang, G., Y. Zhang, J. Dong, and X. Xiao. 2013. Green-up dates in the Tibetan Plateau have continuously advanced from 1982 to 2011. Proceedings of the National Academy of Sciences USA 110:4309-4314.

Zhang, G., X. Xiao, J. Dong, W. Kou, C. Jin, Y. Qin, Y. Zhou, J. Wang, M. A. Menarguez, and C. Biradar. 2015. Mapping paddy rice planting areas through time series analysis of MODIS land surface temperature and vegetation index data. ISPRS Journal of Photogrammetry and Remote Sensing 106:157-171.

Zhang, Y., et al. 2016. Multiple afforestation programs accelerate the greenness in the "Three North" region of China from 1982 to 2013. Ecological Indicators 61:404-412.

Zhou, L., C. J. Tucker, R. K. Kaufmann, D. Slayback, N. V. Shabanov, and R. B. Myneni. 2001. Variations in northern vegetation activity inferred from satellite data of vegetation index during 1981 to 1999. Journal of Geophysical Research: Atmospheres 106:20069-20083.

Zhou, Y., L. Zhang, R. Fensholt, K. Wang, I. Vitkovskaya, and F. Tian. 2015. Climate contributions to vegetation variations in central Asian drylands: Pre- and Post-USSR collapse. Remote Sensing 7:2449-2470.

SUPPORTING INFORMATION

Additional supporting information may be found online at: http://onlinelibrary.wiley.com/doi/10.1002/eap.1660/full

Data Availability

Data available from the Dryad Digital Repository: https://doi.org/10.5061/dryad.12bd9. 